\title{
Effects of Augmented Feedback with Error Self-estimates on Vocational High School Students' Motor Skill Learning
}

\author{
Yi-Fang Lee ${ }^{1}$ - James W. Altschuld ${ }^{2}$. Fang-Shen Chiang ${ }^{3}$. \\ Ching-Syang Jack Yue ${ }^{4,5} \cdot$ Hsiu-Te Sung ${ }^{1} \cdot$ Chun-Hsin Chang ${ }^{6}$
}

Received: 30 March 2020 / Accepted: 25 June 2021 / Published online: 12 August 2021

(c) The Author(s) 2021

\begin{abstract}
The influence of augmented feedback and self-estimation of errors on the welding skill learning of vocational high school students was the focus of this study. A quasi-experimental research design was utilized by randomly assigning two classes of car repair students to an experimental group and a control group. Each participant had 9 practice trials, took 3 tests (pre, post, and delayed), and received augmented feedback 3 times during the skill acquisition phase. The experimental group was additionally requested to self-estimate their errors by reviewing their work in comparison to a benchmark piece, assessing the differences, and completing a checklist of criteria, while the control group did not undergo this process. The performance of participants improved through the practice period with the experimental group showing significantly greater changes than those in the control condition. For the delayed-test, both groups declined to some extent from the post-test, but the experimental subjects did better comparatively. Augmented feedback with self-estimation of errors appeared beneficial for vocational high school students' motor skill learning.
\end{abstract}

Keywords Augmented feedback · Motor skill learning · Self-estimation of error · Vocational education and training

\section{Introduction}

Motor skills are an essential component required of individuals working in all kinds of skilled and hands-on professions. People in vocational and technical workplaces perform specific motor skills, such as hammering a nail, painting a wall, or welding metal. How these skills are learned and what factors enhance motor learning in vocational education are critical for better training of the skilled workforce.

Yi-Fang Lee

ivana@ntnu.edu.tw

Extended author information available on the last page of the article 
Motor skill learning is a complex mental process in response to practice of a certain skill that results in changes in the central nervous system (Lazaro et al., 2013; Wulf, 2012). According to motor-cognitive theories, it usually involves practice, feedback, and knowledge of results (Adams, 1971; Schmidt, 1991). Many studies have probed into influential factors for motor skill learning and performance, highlighting the impact of feedback, self-control of learning, tool use, and so on (Bril, 2015; Schmidt, 1991, 2003). Aspects of the process such as these appear to have informational and motivational effects on skill learning, especially in children's development, sports, neurophysiology, and archaeology and other fields. Their generalisability to motor skill learning in vocational education and training is less evident due to the small number of studies that have been conducted.

Relevant here is a commonly accepted idea that human fallibility is an important source of practice-based learning (Bauer \& Harteis, 2012). Errors can be fruitful for skill improvement based on cognitive and action-oriented approaches (Bauer et al., 2012; Harteis et al., 2012; Keith \& Frese, 2008); research on their use in the learning process is still early in its development and scattered across academic disciplines (Bauer \& Harteis, 2012). More investigation in this regard would enhance the effectiveness of skill learning and training.

The aim of this study was to determine the influence of augmented feedback and self-estimation of errors on the welding skill learning of vocational high school students. It was carried out in an educational setting. Butt welding was its focus because it involves a series of subtle motions of the hands and arms (such as arcing, melting the workpiece, decomposing the flux coating, etc.) and provides an opportunity to observe the influence of augmented feedback and error estimation on performance. The literature was reviewed in relation to motor learning theory, augmented feedback, self-controlled learning with error estimation, and their subsequent effects on motor skill learning. The joint use of the two factors for vocational school students was examined. The procedures are fully explained and discussed and the results shed light on how motor skill learning performance in the vocational skill instruction and training context could be improved.

\section{Literature Review}

\section{Motor Skill Theory}

Two motor-cognitive theories, Adam's closed-loop theory and Schmidt's schema theory, are commonly accepted in the field of motor skill learning. Adams' theory (1971) of skill performance involves two key neural components, memory trace and perceptual trace. Memory trace selects and triggers an appropriate response, while perceptual trace records the movements made during numerous practices. Both during and after attempting a movement, the feedback and knowledge of results allow the performer to compare the movement with the perceptual trace as a referent of correctness. Error adjustments can then be made in the following movements (Kent, 2006). 
Differing from Adam's theory, Schmidt's schema theory is based on the openloop concept. It provides a more parsimonious account of how the different movement variations are produced and stored in memory (Schmidt, 1975). In Schmidt's theory, a movement pattern is produced by a generalised motor program retrieved from memory which is then adapted to a particular situation. For flexibility, the motor system needs to learn the relations between the initial conditions (the distance between the football in the quarterback's hands and the receiver), the generated motor commands (forces that are generated during the throw), the sensory results of the motor commands (proprioception of arm movement), and the movement's outcome (the actual distance that the football is thrown). These relationships are inherent in two motor schemas, recall and recognition.

The former represents the initial conditions, movement parameters and outcomes used to compute and select the appropriate parameters that are required to achieve the movement goal. The latter is used for evaluation, allowing the performer to assess the outcome by comparing it with the received feedback (Wulf, 2012). Schmidt's theory pays more attention to the variability of practice under different conditions, and values the positive benefits for error production, especially learning from one's own mistakes.

Summing up, the two theories emphasize the role played by practice, feedback, knowledge of results, and sensitivity of error-detection processes in the modification of a performer's movements. These components featured prominently in the design of the current study.

\section{Augmented Feedback}

Motor skill learning, important in the performance of daily tasks, could be improved as a result of the quantity and quality of practice (Magill, 2001; Schmidt \& Lee, 1999). Observation of others' practice, feedback, self-controlled practice, and the learner's focus of attention could also affect successful outcomes (Wulf et al., 2010). Feedback that specifically provides information about performance is essential for facilitating learners' correction of errors and attainment of performance goals especially when the learner is motivated and persists (Schmidt, 1991, 2003).

For some time, studies on motor skill learning have looked at augmented feedback, externally presented information about the outcome or characteristic of a movement leading to a particular result. It comes from sources outside of the learner and is often used to supplement task-intrinsic feedback with sensory perceptual information from visual, auditory, proprioceptive, or tactile senses that learners use as cues to understand the outcome of performance (Magill \& Anderson, 2017; Salmoni et al., 1984). Research has suggested that augmented feedback in conjunction with intrinsic feedback would be advantageous for motor skill learning (Mononen, 2007; Schmidt et al., 2018). This is particularly pertinent for tasks where intrinsic information is hard to identify or reach; augmented feedback could be vital to effective skill learning (Magill, 1994). 
Augmented feedback consists of knowledge of results (KR) and knowledge of performance (KP) (Wulf et al., 2010). KR is externally presented information about the outcome of performing a skill, such as a performer's score, position, or time; and $\mathrm{KP}$ is related to the movement in which a skill is performed, such as a comment from the coach about a player's foot placement during a kick in football (Sharma et al., 2016). In early studies, the frequency of KR was mainly looked at in terms of simple tasks (Bilodeau et al., 1959). Later research established that not only is $\mathrm{KR}$ and its frequency important in feedback, but other dimensions come into play when task complexity increases - feedback mode, timing, accuracy, error estimation, and amount at a single moment (Chen et al., 2002; Wulf \& Shea, 2002). The current investigation focused on the importance of one of them, namely self-error estimation.

Most often, augmented feedback is provided solely by instructors, particularly in hands-on vocational education and training (VET) with groups of students as a whole. Instructors establish nearly all of the details of feedback-whether it will be offered, when, how, and with the needed kinds of demonstration. In this scenario students are not as active in learning and are less engaged with the information and activities (Wulf et al., 2010).

\section{Self-Controlled Learning with Error Estimation}

Skill learning could be enhanced when learners have some degree of freedom to control their own practice (Safir et al., 2010). Self-controlled feedback may increase performance by affording information that is helpful to each learner in his/her own construction of knowledge and understanding (Chiviacowsky \& Wulf, 2005; Grand et al., 2015). Chiviacowsky \& Wulf (2002) posited that self-controlled learners may engage in error estimation during practice, and are somewhat independent of external feedback, relying more on their own ability to detect errors. Barros et al. (2019) observed that an error estimation group performed better than its counterpart during the retention and transfer phases. The relationship between error estimation processes and motor skill acquisition was also proposed by Guadagnoli \& Kohl (2001) and Liu and Wrisberg (1997). It is likely that the development of error estimation abilities was helpful in these instances.

Error estimation mainly relies on learners' own feedback and might be difficult in situations where they lack sufficient knowledge to identify what kind of sensory information is most useful for movement correction. Beginners in vocational high school classes are usually not equipped with sufficient optimal strategies to employ in self-directed learning or in identifying errors. For them, augmented feedback with the addition of self-estimation of error might help overcome such a weakness. It might further aid in creating and testing hypotheses regarding goal achievement or action adjustment in subsequent trials if needed, thus leading to better performance (Barros et al., 2019; Swinnen et al., 1990). 
Much skill performance requires the use of tools to complete tasks, for example, the use of a hammer for nailing. A functional lens on the use of implements comes from anthropology where an elementary action (the use of the tool) is processed through a sequence of interconnected movements linked to the goal of the task (Bril et al., 2005). For example, from studies on the percussive actions involved in stone knapping and nut cracking Bril et al. (2012) identified four parameters. The first deals with task constraints such as kinetic energy, while the others are under the control of the actor. The second layer relates to control (velocity at impact), the third to regulatory parameters (muscular effort) and the fourth is about movement (muscle activity).

When required to perform a goal-directed action, an actor has to assess the current state of the body and of the tools required to successfully produce the functional parameters. Then he/she needs to learn to use his/her visual and haptic senses to explore and to capture the necessary information for performing. In other words, a person has to develop the capacity to detect the constraints and opportunities involved in completing a task. The learning process then is one of discovering and gradually mastering the functional properties of the task necessary for its completion. It requires acquiring information about a specific context via an enhanced detection process (Reed, 1993). The self-estimation of errors discussed earlier could be seen as an information detection mechanism in motor skill learning.

Butt welding in high school vocational training classes is an example of a motor skill area in which augmented feedback with error self-estimation could be used to enhance learning. In it two pieces of metal are attached to each other via different types of welding electrodes (use of tools). Indicators of successful work are the evenness and appropriateness of the width and height of the weld zone, the straightness of the fusion line, the resistance of the joint, and so on (Department of Training \& Workforce Development, 2008). Because the process produces radiation, full body protective clothing is required. Under this condition, intrinsic feedback from sensory perception is difficult to observe directly, particularly for beginners who lack the capacity to see critical errors or who have limited information (Mononen, 2007). An augmented process via error self-estimation should enrich learners' adaptation to the contextual properties of the task and should be of use for learning the subtle movements of welding. Using tangible measurement criteria for students to follow would also give them a better sense of their strengths and deficiencies.

We studied the impact of augmented feedback with self-estimated errors on learners' welding skill performance in a vocational training context. The results should expand understanding of the impact of the joint use of these procedures for the improvement of motor skill learning. It was expected to contribute to the way in which vocational schools train their students. 


\section{Method}

\section{Sampling}

A purposeful sampling strategy was conducted. Two $10^{\text {th }}$ grade classes in a vocational high school in Taiwan constituted the sample for this research. They consisted of students enrolled in a three-year auto repair program aimed at cultivating grassroots talents in the car repair industry. Butt welding is seen as a very suitable skill area in which to test out the independent variables and this vocational high school had a history of long-term cooperation with the researchers and was committed to participating in the experiment.

The sample had 41 male $10^{\text {th }}$ graders around 15 to 16 years old. Since vocational senior high school in Taiwan starts from $10^{\text {th }}$ grade, the students had only half a year of learning experience in fundamental knowledge and training of mechanical works, without any working experience in car-related workplaces. Overall, they were beginners in the field of power mechanical engineering. An investigation before the experiment showed that the students had no prior exposure to butt welding. Thus, the two classes were randomly assigned to either an experimental or a control group, with 20 and 21 participants, respectively. They all signed an informed consent form in accordance with the guidelines of the local ethics commission.

\section{Experimental Design}

A quasi-experimental research design was utilized. The experimental group received augmented feedback and self-estimated their errors when welding, whereas the control group received augmented feedback only. Specifically, all participants watched an instructional video in which the welding knowledge, equipment, jointing method, manual welding procedure, and grading criteria were presented. After that, they took a pre-test, consisting of one welding trial with no feedback and without a benchmark comparison welding piece, followed by a practice phase of nine learning trials, during which augmented feedback was provided three times (on the first, fourth and seventh trials) for both groups.

At these three trials, the experimental group received augmented feedback (their welding work and a benchmark comparative welding piece), and were also required to self-estimate their errors. This was accomplished through comparing their own work and a benchmark, detecting errors, and thinking about the possible causes by completing a checklist of grading criteria (see Appendix; more detailed information is presented in the grading criteria section). The students had to check either 'Achieved' or 'Needs Improvement' for each criterion. It was assumed that students could make appropriate self-estimation of their errors and try to correct their motor skills in the following trials. The whole process required about $2 \mathrm{~h}$ for each participant.

The control group received augmented feedback on their own work on the first, fourth, and seventh trials as did the experimental group, but did not go through the error estimation process. Following the nine practice trials, 
both groups were re-evaluated twice-an immediate post-test and a delayed one a week later. It is worth noting that the frequency of learning trials (9) was recommended by two of the sample's instructors who were familiar with the skill level of the 41 students. Overall, the conditions that systematically varied during the experiment were the augmented feedback accompanied with self-estimation of errors on three trials. They were assumed to be conducive to students' welding performance in terms of the grading criteria described in the following section. The experimental design is shown in Table 1.

\section{Butt Welding Skill}

The butt welding technique, the target motor skill, was taught through a videoguided instructional approach, ensuring that the two groups received equal exposure to it and had exactly the same knowledge and skill demonstration. The video, produced by the research team, included an introduction of the fundamentals and application of welding skill, welding equipment, machines and tools, procedures, tips for welding practice, safety and caution when doing the task, and criteria for assessing performance.

The welding process in the video was demonstrated by an expert. It started by creating an arc between the tip of the electrode and the workpiece using a low voltage, high amperage current flow. Heat for welding was generated from this arc, melting the workpiece and the electrode tip, decomposing the flux coating on the electrode and generating a gaseous shield which protected the weld pool and the surrounding hot metal from the atmosphere. The electrode then melted off, forming droplets which transferred across the arc, adding to the molten parent metal and becoming the weld metal upon solidification (Department of Training \& Workforce Development, 2008). When the welding work was completed, the weld zone was covered with welding which had to be clipped off for a clear view of the outcome. Figure 1 is an illustration of the angle and path of the welding technique in the instructional video. The left-hand side of Fig. 2 presents one participant's practice situation, and the right side is a sample of a benchmark piece of welding work.

Table 1 Experimental design procedure

\begin{tabular}{lllll}
\hline Group & Pre-test & Practice phase & Post-test & $\begin{array}{l}\text { Delayed-test } \\
(1 \text { week } \\
\text { later })\end{array}$ \\
\hline Experimental & $\mathrm{O}$ & $\mathrm{X} 1\left(\mathbf{O}_{1}, \mathrm{O}_{2}, \mathrm{O}_{3}, \mathbf{O}_{4}, \mathrm{O}_{5}, \mathrm{O}_{6}, \mathbf{O}_{7}, \mathrm{O}_{8}, \mathrm{O}_{9}\right)$ & $\mathrm{O}$ & $\mathrm{O}$ \\
Control & $\mathrm{O}$ & $\mathrm{X} 2\left(\mathbf{O}_{1}, \mathrm{O}_{2}, \mathrm{O}_{3}, \mathbf{O}_{4}, \mathrm{O}_{5}, \mathrm{O}_{6}, \mathbf{O}_{7}, \mathrm{O}_{8}, \mathrm{O}_{9}\right)$ & $\mathrm{O}$ & $\mathrm{O}$ \\
\hline
\end{tabular}

\footnotetext{
${ }^{\text {a }}$ Augmented feedback provided on the $1^{\text {st }}, 4^{\text {th }}$ and $7^{\text {th }}$ trials during practice for both groups; at these three points, the experimental group additionally self-estimated their errors after receiving the augmented feedback, while the control group did not
} 

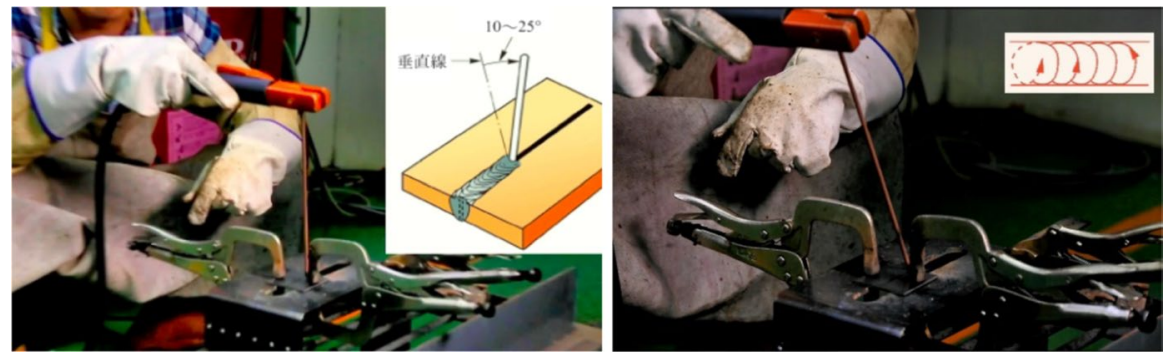

Fig. 1 Demonstrations of the angle (left-hand side) and path (right-hand side) of the welding technique
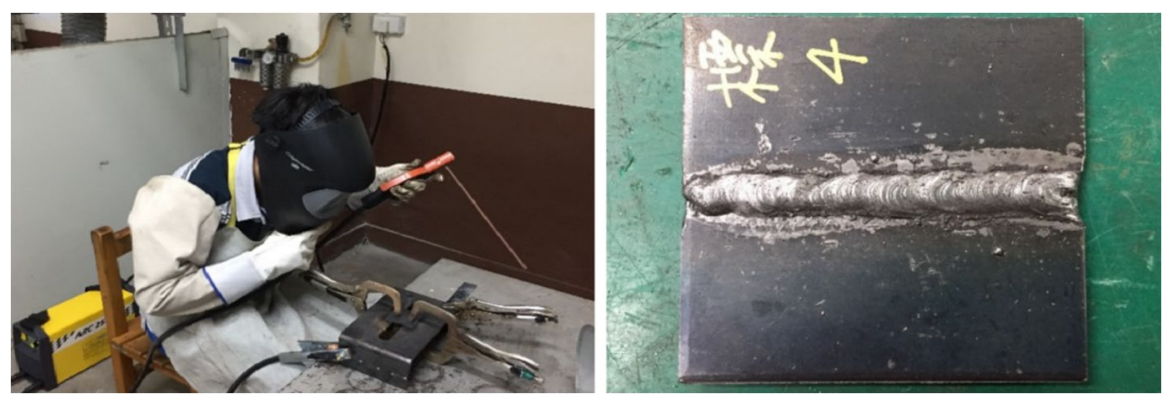

Fig. 2 One participant's practice situation (left) and a sample of a benchmark piece (right)

\section{Grading Criteria}

Welding products were evaluated in accordance with six criteria totalling 100 points: the weld zone is appropriate and uniform (20 points), the weld corrugation is fine and uniform (20 points), the weld's progress is in the right position (20 points), the weld is in a straight line (10 points), the welding work is completed correctly (10 points), and overall performance ( 20 points). These criteria were generated by two experts according to the 'Basic manual metal arc welding' guidelines issued by the Department of Training and Workforce Development (2008). The experts were medallists in automobile technology in the WorldSkills Competition and had welding certification. They had teaching experience in the car repair program in the vocational high school and understood the sample's ability to carry out the welding task. Both were qualified to serve as the criteria developers and graders in this study.

Before the experiment, the experts were asked to grade three pieces of welding work separately then to discuss the ratings to develop consensus for judgement. Each piece of student work was independently assessed by them. Inter-rater reliability was acceptable, and the Pearson correlation coefficients between the two ratings across all trials and tests ranged from 0.62 to $0.76(p<0.05)$, indicating that the judgements were made in a relatively consistent manner. The average scores of the two experts' ratings were used for the following analysis. 


\section{Data Analysis Technique}

Statistical analyses (two-way mixed ANOVA) were performed using the IBM Statistical Package for the Social Sciences (SPSS) 21 version. A two-way mixed ANOVA is often used in studies where a dependent variable is measured over two or more time points ('time' is a within-subjects factor), and when subjects have been assigned into two groups that undergo different interventions ('group' is a betweensubjects factor). In this study, participants were assigned into the experimental or control group (between-subjects factor) and their welding performance was measured over nine trials (within-subjects factor) during the practice phase. The primary purpose of a two-way mixed ANOVA is to understand if there is an interaction between 'Group' and 'Trial' in the welding performance. If there is none, a followup test will determine whether any change in the welding performance is simply due to the 'Group' or 'Trial' effect.

For the ANOVA, assumptions of normality and heterogeneity of variances were checked for each group by the Shapiro-Wilk and Levene's tests. All $p$-values in the Shapiro-Wilk tests were greater than 0.05 , and the $F$ values for all Levene's tests ranged from 0.03 to 2.59 , with $p$-values higher than 0.05 . The assumptions were not violated. The mixed model ANOVAs have two assumptions: one is the homogeneity of the variance-covariance matrices, and the other is sphericity. In this case, the Box's test result (Box's $M=80.25, F=1.34, p=0.07$ ) met the homogeneity requirement, indicating that the observed covariance matrices of the dependent variables were equal across groups. The sphericity assumption was violated (Mauchly's $W=0.15, p<0.05$ ), so the Greenhouse-Geisser correction was used to produce a valid $F$-ratio.

\section{Results}

\section{Descriptive Statistics}

The mean values $(M)$ and standard deviations $(S D)$ for each group across different trials are given in Table 2. An independent $t$ test revealed a significant difference between the pre-test scores of the two groups, with the control group having a significantly higher pre-test score $(M=37.98, S D=18.34)$ than the experimental group $(M=27.25, S D=11.52), t(39)=2.23, p=0.03$.

Because of the group difference in the pre-test, the scores from all practices, posttest, and delayed test were replaced with progressive values by subtracting the first trial score (baseline) in the practice phase from each of the successive trials to eliminate the initial group difference on the following ANOVA tests. More specifically, instead of the original ratings, participants' improvement at each of the individual trials, that is, the change between each trial and the baseline (the $1^{\text {st }}$ trial score), was taken into account in the subsequent examinations. Therefore, the group difference in the beginning was controlled, and only changes between each trial and the baseline were analysed to identify the treatment effect. Table 3 presents the descriptive 


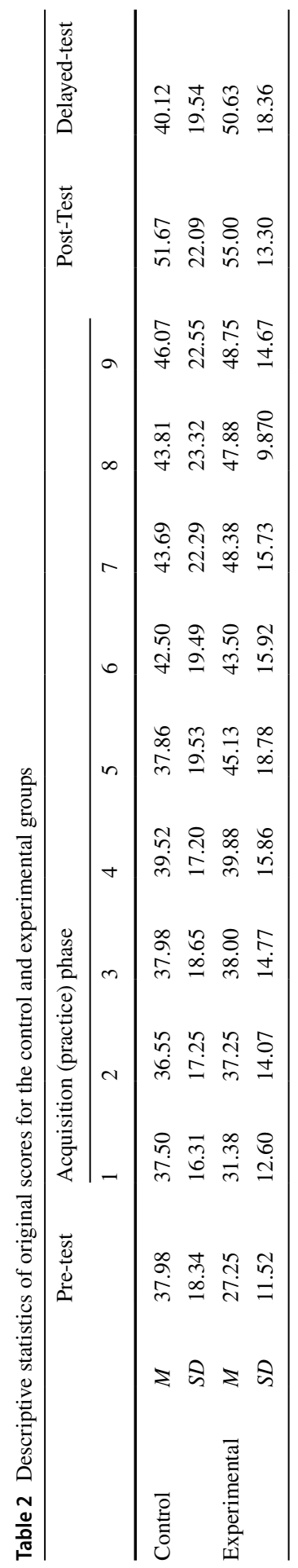




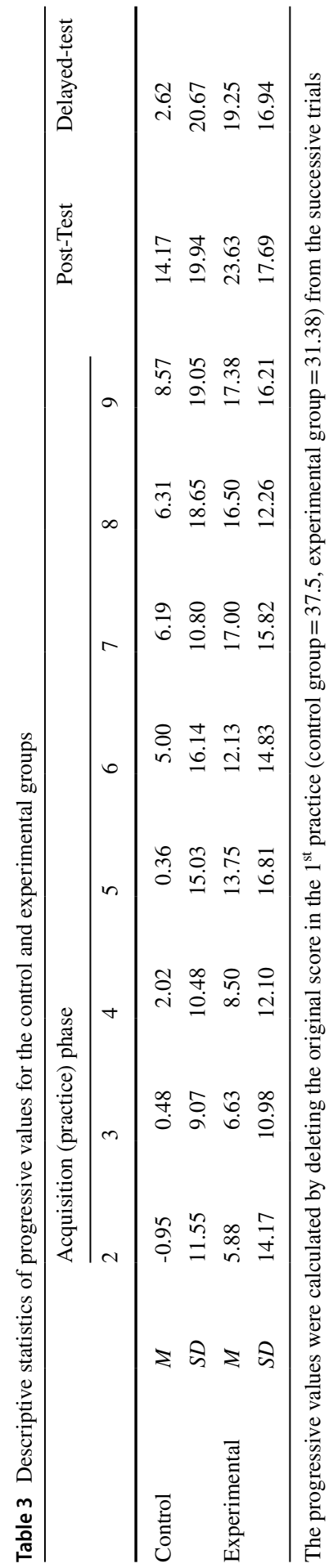


statistics of progressive values at the trials from the second practice in the acquisition phase through the post- and delayed- test, where the original score from the first practice is the baseline.

In Fig. 3, the trend of the experimental and control groups' improvement during the acquisition phase and post-test, based on the progressive values in Table 3, is depicted. Obviously, both groups made progress during the learning period and post-test performance, but the experimental group had greater improvement across trials (excluding the delayed test) than the control group, with a larger intercept $(M=5.88$ vs. $M=-0.95)$ and slope (the ratio was 1.67 to 1$)$.

\section{Results of Main Effects and Interaction}

The results of the two-way mixed ANOVA are in Table 4. The interaction between Trial and Group did not reach a significant level, $F(5.05,196.90)=0.51, p=0.77$, $\eta^{2}=0.01$, signifying that there were no combined effects of the two independent factors (Trial and Group) on the welding performance. As in Fig. 3, the trend of progressive values in each group was relatively parallel and increasing, so it was reasonable to infer that the butt welding performance of all participants improved over the period of practice.

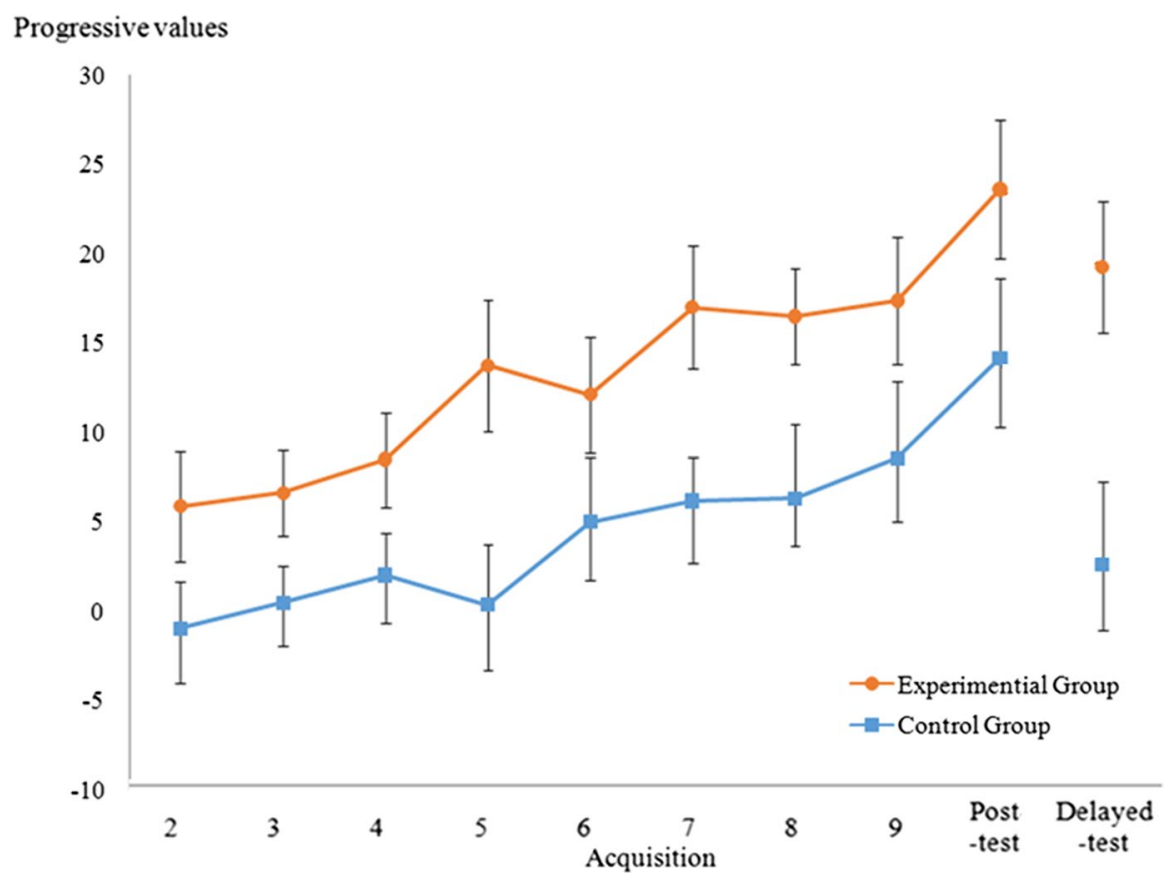

Fig. 3 Progressive values from the practice phase through the post-test for the experimental and control groups 
Table 4 Two-way mixed ANOVA results

\begin{tabular}{lclrlll}
\hline & $\begin{array}{l}\text { Type III Sum of } \\
\text { Squares }\end{array}$ & $d f$ & \multicolumn{1}{l}{$M S$} & $F$ & Sig & Eta squared \\
\hline Group & 7145.39 & 1 & 7145.39 & 6.72 & 0.01 & 0.15 \\
Trial & 8836.82 & 5.05 & 1750.27 & 9.50 & 0.001 & 0.12 \\
Trial× Group & 477.62 & 5.05 & 94.60 & 0.51 & 0.77 & 0.01 \\
Error & & & & & & \\
$\quad$ Between subject & $41,462.17$ & 39 & 1063.13 & & & \\
$\quad$ Residual & $36,260.56$ & 196.90 & 184.15 & & & \\
\hline
\end{tabular}

For the group comparison, the main effect of Group was significant, $F(1$, $39)=6.72, p=0.01, \eta^{2}=0.15$; the experimental group had greater improvement in welding performance than the control group. The main effect of Trial was also significant, $F(5.05,196.90)=9.50, p=0.001, \eta^{2}=0.20$. A follow-up test of paired comparisons revealed that the progressive values in the post-test were significantly greater than those in each of the sequential trials from the second to the sixth.

\section{Results of the Delayed Test}

One week after the nine trials and the post-test, the students took a delayed test to measure retention of skill acquisition. The progressive value (difference between the delayed test and the $1^{\text {st }}$ trial during the practice phase) was 19.5 in the experimental group and 2.62 in the control group. This difference reached a significant level of 0.05 , according to the one-way ANOVA results $(F(1,39)=7.90, p=0.008$, $\left.\eta^{2}=0.17\right)$, so the experimental group that experienced the error estimation process retained the skill better one week later than the counterpart group which did not have the same experience. As expected, delayed-test scores declined in each group when compared to the post-test; the drop was significant in the control group (mean difference $=11.55, t(20)=3.52, p=0.002$ ), but not in the experimental group (mean difference $=4.38, t(19)=0.89, p=0.39$ ) via the repeated measures $t$ test. This strengthened the finding that the experiment had an impact.

\section{Discussion}

The purpose of the study was to shed light on the benefits of practice with augmented feedback and self-estimation of error for motor skill learning in a vocational education setting. All participants received augmented feedback, with the experimental group going one step further by estimating and detecting errors (3 times) through comparing their own work with a benchmark and completing a list of grading criteria.

The butt welding performance of all participants improved over the course of the experiment, indicating benefits from providing external augmented feedback. It is noticeable that intrinsic learning in this experiment may be inhibited by the welding 
procedures themselves. The participants were required to wear protective clothing to protect them from the radiated heat and rays associated with the process. The clothing (auto-darkening welding helmet, leather shoe cover, flame-proof gloves) obstructed the participants' sensory receptors, perhaps preventing them from receiving immediate intrinsic feedback. Under such conditions, augmented information might play a much more important role in feedback provision. In conjunction with this is the fact that the weld zone was covered with slag which hindered the direct observation of welding outcomes. That is, information from task-intrinsic sources may have been insufficient to determine the appropriateness of the individuals' welding performances. To provide meaningful KR feedback, the research team members chipped off the slag right after the welding work was completed and presented it to the learners before the next trial so they could directly see their welding outcomes and make corrections in subsequent practice. Obviously, this augmented feedback was vital, as it supplemented other information and effectively facilitated skill learning, particularly for tasks in which feedback is critical but cannot be adequately assessed by the learners (Magill, 1994; Mononen, 2007).

In agreement with previous studies, the experimental group performed better than the control group, pointing toward a combined positive effect of augmented feedback with self-estimation of error on welding skill acquisition (Swinnen, 1990; Swinnen et al., 1990). Participants who estimated errors did better than those who did not. It is possible that error estimation requires individuals to create a hypothesis about their previous work, thereby encouraging the use of memory and KR to test the hypothesis. Accordingly, a person's involvement in feedback and the way of using it cannot be independent of each other (Khodadost et al., 2015). Specifically, after receiving feedback on performing a movement, the individual would compare performance with criteria in detecting errors, and then use the information to amend subsequent movements. Those who had the capability and opportunity to self-estimate errors were able to make comparisons and perform more appropriate future actions.

Although the scores in both groups declined for the delayed test, the experimental group scored higher relative to the control group. This finding aligned with previous studies about the advantages of self-estimation of movement errors for performing more cognitive or information processes and developing error detection capability, such as observing differences, identifying possible causes, and hypothesizing solutions for the next trials, leading to skill consolidation and retention in delayed tests (Barros et al., 2019; Hogan \& Yanowitz, 1978; Swinnen, 1990).

\section{Conclusions, Limitations and Suggestions for Further Research}

\section{Conclusions}

This study is supportive of the proposition that augmented feedback with self-estimation of errors benefitted the learning of butt welding techniques by vocational high school students early in their educational program. It is notable that augmented feedback can be particularly helpful when intrinsic feedback may not be or is not possible. What was found here underscores that vocational training instructors 
should be attentive to the types of feedback that learners receive during skill acquisition and make good use of augmented feedback. In addition, the error estimation process that guided students to self-reflect on their practice, identify their performance errors, and correct their movements for following trials led to greater engagement in cognitive and metacognitive processes, and deeper information processing that, in turn, contributed to motor skill learning. The findings make a contribution to the vocational and training area by highlighting the importance of learners' selfestimation of errors and encouraging instructors to help students engage in better error detection.

\section{Limitations and Suggestions for Further Research}

Some limitations to this study should be noted. One is due to how vocational high schools operate in Taiwan. Classrooms instead of individual students had to be the sampling units because the random assignment of subjects was not possible. This resulted in non-equivalent groups which was accounted for by subtracting the first trial score in the practice phase from each of the successive trials. These values represented progression between trials adjusted for the scores in the first trial, thus controlling for group difference in subsequent ANOVA tests. In future investigations it would be desirable to have random assignment of participants to groups if at all possible to ameliorate potential sources of invalidity.

The second issue relates to the number of practices and amount of time. According to theories, motor learning consists of three major stages: cognitive (gathering information to develop an overall understanding of a skill), associative (putting action together to demonstrate a refined movement through practice), and autonomous (performing a skill in any environment with little cognitive involvement compared to the first stage) (Fitts \& Posner, 1967). The stages involve a set of internal processes associated with practice or experience leading to relatively permanent changes in skilled behaviour (Schmidt et al., 2018). In the current case, due to the school teaching schedule, each participant was allotted only nine times to practice within two hours in the acquisition phase. The delayed test showed lower scores for both groups, suggesting that the acquired welding skill might not have been fully incorporated into the students' repertoire, resulting in weaker performance after a period of time. Perhaps the short-term, intensive learning trials need to be lengthened in number or duration.

The third concern was the number of participants who could be accommodated in this study. In order to control for the confounding of school as a variable, students were recruited from one school with the same learning background (major area, school year, skill learning experience, etc.), so there was a small number of participants. This accommodated just one experimental group (augmented feedback with self-estimation of errors) and one control group (augmented feedback only). No additional groups, such as one without augmented feedback, could be created to decompose the impact of augmented feedback or error-estimation alone. Expanding to multiple sites with similar conditions might have overcome this difficulty. 
Another consideration relates to the type of augmented feedback provided. Augmented feedback comes in two types, 'knowledge of performance' (KP) and 'knowledge of results' (KR). KP feedback gives the learners information about how they perform a skill. With welding as an example, it involves many actions and steps, and KP is information related to the initial arcing action, travelling along the welding zone, ending movement as the task is completed, and other actions that produce a successful weld. When using KR feedback, instead of telling the learners what they performed correctly or incorrectly, they received information about how close their workpiece came to the goal. Researchers have proposed that both types of feedback are vital for motor skill learning (Mononen, 2007; Schmidt \& Lee, 1999). In this study only KR was taken into consideration. Future research might incorporate KP feedback to further delve into the results.

Finally, since the timing and choice of whether to conduct self-estimation of error in this study were pre-decided by the researchers, their effects are essentially confounded. Chiviacowsky and Wulf (2005) and Carter et al. (2014) found that timing (before or after skill completion) had a significant influence on performance. Participants who were asked to make the decision after a trial was completed (the self-after group) performed better than their counterparts (the self-before group) who made the decision before a trial. They argued that the self-after group was likely engaged in error estimation on activities with the goal of determining if the KR would provide beneficial information. The self-before group was not as likely to be involved in such a cognitive process, since they made the decision without further information to evaluate its contribution. Such variations in the self-estimation of error might contribute to skill learning differentially, but were not examined in this study. They warrant further research.

Even with these limitations, this study adds much of value to the literature. This experiment yielded important information about the combined use of augmented feedback and the self-estimation of errors in learning a complex, utilitarian vocational skill. This was seldom explored in existing studies, the majority of which examined a single factor only. In addition, understanding of the feedback effect on skill learning was extended beyond fields that most studies are interested in (physical education, exercise and sports science, fine and gross motor skills in child development, and archaeology) to the vocational education context. Future research should replicate this study with other complex skills taught in vocational training and other populations to see if the findings hold and are generalizable.

Lastly, instructors in vocational education and training should be aware of how students use error estimation in motor skill learning particularly for beginners. They are encouraged to prepare valid scoring rubrics including specific criteria and clear descriptions of skill performance for specific tasks and to provide them to students in advance as a guide for self-evaluating performance and adjusting actions in subsequent trials. Instructors could also compare their scores/ratings with those of students, identify differences therein, and delve into why that might be the case to generate informative feedback for instruction. 


\section{Appendix}

\section{Appendix A}

Students' checklist of grading criteria

ID:

Please compare your welding work with the benchmark piece based on the criteria

below at the 1st, 4 th and 7 th trials during the practice phase. Check your performance

in terms of 'Achieved' or 'Needs improvement' for each criterion.

\begin{tabular}{|l|l|l|l|l|l|l|}
\hline \multirow{2}{*}{ Criteria } & \multicolumn{2}{c|}{$1^{\text {st }}$ trial } & \multicolumn{2}{c|}{$4^{\text {th }}$ trial } & \multicolumn{2}{c|}{$7^{\text {th }}$ trial } \\
\cline { 2 - 6 } & Achieved & $\begin{array}{c}\text { Needs } \\
\text { improvement }\end{array}$ & Achieved & $\begin{array}{c}\text { Needs } \\
\text { improvement }\end{array}$ & Achieved & $\begin{array}{c}\text { Needs } \\
\text { improvement }\end{array}$ \\
\hline $\begin{array}{l}\text { The weld zone is } \\
\text { appropriate and uniform. }\end{array}$ & & & & & & \\
\hline $\begin{array}{l}\text { The weld corrugation is } \\
\text { fine and uniform. }\end{array}$ & & & & & & \\
\hline $\begin{array}{l}\text { The weld's progress is in } \\
\text { the right position. }\end{array}$ & & & & & & \\
\hline $\begin{array}{l}\text { The weld is in a straight } \\
\text { line. }\end{array}$ & & & & & & \\
\hline $\begin{array}{l}\text { The welding work is } \\
\text { completed correctly. }\end{array}$ & & & & & & \\
\hline $\begin{array}{l}\text { Overall performance is } \\
\text { satisfactory. }\end{array}$ & & & & & & \\
\hline
\end{tabular}

Acknowledgements This work was financially supported by the Ministry of Science and Technology in Taiwan (Grant No. MOST 105-2511-S-003-009-MY2) and by the National Taiwan Normal University (NTNU) within the framework of the Higher Education Sprout Project by the Ministry of Education (MOE) in Taiwan.

Data Availability Not applicable.

Code Availability Not applicable.

\section{Declarations}

This article followed the ethical rules stipulated for research in the social sciences by the Ministry of Science and Technology in Taiwan.

Conflicts of Interest The authors declare that they have no conflict of interest.

Open Access This article is licensed under a Creative Commons Attribution 4.0 International License, which permits use, sharing, adaptation, distribution and reproduction in any medium or format, as long as you give appropriate credit to the original author(s) and the source, provide a link to the Creative Commons licence, and indicate if changes were made. The images or other third party material in this article 
are included in the article's Creative Commons licence, unless indicated otherwise in a credit line to the material. If material is not included in the article's Creative Commons licence and your intended use is not permitted by statutory regulation or exceeds the permitted use, you will need to obtain permission directly from the copyright holder. To view a copy of this licence, visit http://creativecommons.org/licen ses/by/4.0/.

\section{References}

Adams, J. A. (1971). A closed-loop theory of motor learning. Journal of Motor Behavior, 3, 111-150.

Barros, J. A. C., Yantha, Z., Carter, M. J., Hussein, J., \& Ste-Marie, D. M. (2019). Examining the impact of error estimation on the effects of self-controlled feedback. Human Movement Science, 63, 182-198.

Bauer, J., Gartmeier, M., \& Harteis, C. (2012). Human fallibility and learning from errors at work. In J. Bauer \& C. Harteis (Eds.), Human Fallibility (pp. 155-169). Springer.

Bauer, J., \& Harteis, C. (2012). The ambiguity of errors for work and learning: Introduction to the volume. In J. Bauer \& C. Harteis (Eds.), Human Fallibility (pp. 1-14). Springer.

Bilodeau, E. A., Bilodeau, I. M., \& Schumsky, D. A. (1959). Some effects of introducing and withdrawing knowledge of results early and late in practice. Journal of Experimental Psychology, 58, 142144. https://doi.org/10.1037/h0040262

Bril, B., Roux, V., \& Dietrich, G. (2005). Stone knapping: Khambhat (India), a unique opportunity? In V. Roux \& B. Bril (Eds.), Stone knapping: The necessary conditions for a uniquely hominid behavior (pp. 53-72). McDonald Press.

Bril, B., Smaers, J., Steele, J., Rein, R., Nonaka, T., Dietrich, G., Biryukova, E., Hirata, S., \& Roux, V. (2012). Functional mastery of percussive technology in nut-cracking and stone-flaking actions: Experimental comparison and implications for the evaluation of the human brain. Philosophical Transaction of the Royal Society: Biology, 367, 59-74. https://doi.org/10.1098/rstb.2011.0147

Bril, B. (2015). Learning to use tools: A functional approach to action. In L. Fillietaz \& S. Billet (Eds.), Francophone perspectives of learning through work: Conceptions, traditions and practices (pp. 95-118). Springer.

Carter, M. J., Carlsen, A. N., \& Ste-Marie, D. M. (2014). Self-controlled feedback is effective if it is based on the learner's performance: A replication and extension of Chiviacowsky and Wulf (2005). Frontiers in Psychology, 5, 1325. https://doi.org/10.3389/fpsyg.2014.01325

Chen, D., Hendrick, J. L., \& Lidor, R. (2002). Enhancing self-controlled learning environments: The use of self-regulated feedback information. Journal of Human Movement Studies, 43(1), 69-86.

Chiviacowsky, S., \& Wulf, G. (2002). Self-controlled feedback: Does it enhance learning because performers get feedback when they need it? Research Quarterly for Exercise and Sport, 73, 408-415. https://doi.org/10.1080/02701367.2002.10609040

Chiviacowsky, S., \& Wulf, G. (2005). Self-controlled feedback is effective if it is based on the learner's performance. Research Quarterly for Exercise and Sport, 76, 42-48. https://doi.org/10.1080/02701 367.2005.10599260

Department of Training and Workforce Development. (2008). Basic manual metal arc welding. Accessed 2019/7/28 Retrieved from http://www.dtwd.wa.gov.au/sites/default/files/teachingproducts/ENG722_ CCBY.PDF

Fitts, P. M., \& Posner, M. I. (1967). Human performance. Brooks and Cole.

Grand, K. F., Bruzi, A. T., Dyke, F. B., Godwin, M. M., Leiker, A. M., Thompson, A. G., Buchanan, T. L., \& Miller, M. W. (2015). Why self-controlled feedback enhances motor learning: Answers from electroencephalography and indices of motivation. Human Movement Science, 43, 23-32. https:// doi.org/10.1016/j.humov.2015.06.013

Guadagnoli, M. A., \& Kohl, R. M. (2001). Knowledge of results for motor learning: Relationship between error estimation and knowledge of results frequency. Journal of Motor Behavior, 33, 217-224.

Harteis, C., Bauer, J., \& Heid, H. (2012). Research on human fallibility and learning from errors at work: Challenges for theory, research, and practice. In J. Bauer \& C. Harteis (Eds.), Human Fallibility (pp. 255-265). Springer. 
Hogan, J. C., \& Yanowitz, B. A. (1978). The role of verbal estimates of movement error in ballistic skill acquisition. Journal of Motor Behavior, 10, 133-138.

Keith, N., \& Frese, M. (2008). The effectiveness of error management training: A meta-analyses. Journal of Applied Psychology, 93, 59-69.

Kent, M. (2006). The Oxford dictionary of sports science and medicine (3rd ed.). Oxford University Press.

Khodadost, H., Zareian, E., Arani, H. K., Nosh-abadi, R. N., \& Mashreghi, R. A. (2015). Effect of two types of feedback and error estimation on error detection capability in continuous tracking task. Biological Forum - an International Journal, 7(1), 198-204.

Lazaro, R. T., Reina-Guerra, S. G., \& Quiben, M. (2013). Umphred's neurological rehabilitation (7th ed.). Elsevier.

Liu, J., \& Wrisberg, C. A. (1997). The effect of knowledge of results delay and the subjective estimation of movement form on the acquisition and retention of a motor skill. Research Quarterly for Exercise and Sport, 68(2), 145-151.

Magill, R. A. (1994). The influence of augmented feedback during skill learning depends on characteristics of the skill and the learner. Quest, 46, 314-327. https://doi.org/10.1080/00336297.1994. 10484129

Magill, R. A. (2001). Augmented feedback in motor skill acquisition. In R. N. Singer, H. A. Hausenblas, \& C. M. Janelle (Eds.), Handbook of Sport Psychology (2nd ed., pp. 86-114). Wiley.

Magill, R. A., \& Anderson, D. I. (2017). Motor learning and control: Concepts and applications (11th ed.). McGraw-Hill.

Mononen, K. (2007). The effects of augmented feedback on motor skill learning in shooting: A feedback training intervention among inexperienced rifle shooters. University of Jyväskylä.

Reed, E. S. (1993). The intention to use a specific affordance: A conceptual framework for psychology. In R. H. Wozniak \& K. W. Fischer (Eds.), Development in context: Acting and thinking in specific environments (pp. 45-76). Lawrence Erlbaum associates.

Safir, O., Dubrowski, A., Hui, Y., Backstein, D., \& Carnahan, H. (2010). Self-directed practice scheduling is equivalent to instructor guided practice when learning a complex surgical skill. Procedia Social and Behavioral Sciences, 2, 792-796. https://doi.org/10.1016/j.sbspro.2010.03.105

Salmoni, A. W., Schmidt, R. A., \& Walter, C. B. (1984). Knowledge of results and motor learning: A review and critical reappraisal. Psychological Bulletin, 9(5), 355-386.

Schmidt, R. A. (1975). A schema theory of discrete motor skill learning. Phycological Review, 82(4), $225-260$.

Schmidt, R. A. (1991). Motor learning principles for physical therapy. In M. Lister (Ed.), Contemporary management of motor control problems: Proceedings of the II STEP conference ( $\mathrm{pp}$. 49-64). Foundation for Physical Therapy.

Schmidt, R. A. (2003). Motor schema theory after 27 years: Reflections and implications for a new theory. Research Quarterly for Exercise and Sport, 74, 366-375.

Schmidt, R. A., \& Lee, T. D. (1999). Motor control and learning: A behavioural emphasis. Human Kinetics.

Schmidt, R. A., Lee, T. D., Winstein, C. J., Wulf, G., \& Zelaznik, H. N. (2018). Motor control and learning (6th ed.). Human Kinetics.

Sharma, D. A., Chevidikunnan, M. F., Khan, F. R., \& Gaowgzeh, R. A. (2016). Effectiveness of knowledge of result and knowledge of performance in the learning of a skilled motor activity by healthy young adults. Journal of Physical Therapy Science, 28(5), 1482-1486. https://doi.org/10. 1589/jpts.28.1482

Swinnen, S. P. (1990). Interpolated activities during the knowledge-of-results delay and post-knowledge-of-results interval: Effects on performance and learning. Journal of Experimental Psychology: Learning, Memory, and Cognition, 16, 692-705. https://doi.org/10.1037/0278-7393.16.4. 692

Swinnen, S. P., Schmidt, R. A., Nicholson, D. E., \& Shapiro, D. C. (1990). Information feedback for skill acquisition: Instantaneous knowledge of results degrades learning. Journal of Experimental Psychology: Learning, Memory, and Cognition, 16, 706-716. https://doi.org/10.1037//02787393.16.4.706

Wulf, G. (2012). Motor Schema. In N. M. Seel (Ed.), Encyclopaedia of the Sciences of Learning. Springer. https://doi.org/10.1007/978-1-4419-1428-6_870 
Wulf, G., \& Shea, C. (2002). Principles derived from the study of simple skills do not generalize to complex skill learning. Psychonomic Bulletin \& Review, 9, 185-211. https://doi.org/10.3758/ BF03196276

Wulf, G., Shea, C., \& Lewthwaite, R. (2010). Motor skill learning and performance: A review of influential factors. Medical Education, 44, 75-84. https://doi.org/10.1111/j.1365-2923.2009.03421.x

Publisher's Note Springer Nature remains neutral with regard to jurisdictional claims in published maps and institutional affiliations.

Yi-Fang Lee , Ph.D., is a professor at the Department of Industrial Education at National Taiwan Normal University in Taiwan. Her research interests focus on needs assessment, program evaluation, comparative education, vocational and technical skill learning and assessment.

James W. Altschuld , Ph.D., is a professor emeritus at The Ohio State University. He has presented and published extensively on evaluation topics, especially on needs assessment and the evaluation of science and technology education.

Fang-Shen Chiang , Ph.D., is a professor emeritus at the Department of International and Comparative Education at National Chi Nan University, Taiwan. His research interests focus on school effectiveness, cross-national comparison of school learning and factors influencing student achievement.

Ching-Syang Jack Yue , Ph.D., is a professor at the Department of Statistics at National Chengchi University. His research interests focus on statistical computing, demography, game theory, and spatial statistics.

Hsiu-Te Sung , Ph.D., is a professor at the Department of Industrial Education at National Taiwan Normal University in Taiwan. His research interests focus on policy and reform on vocational and technical education, and total quality management.

Chun-Hsin Chang is an assistant professor at the Undergraduate Program of Vehicle and Energy Engineering at National Taiwan Normal University in Taiwan. His research interests focus on automobile technology, vocational and technical skill learning.

\section{Authors and Affiliations}

\section{Yi-Fang Lee ${ }^{1}$ (D) James W. Altschuld ${ }^{2}$. Fang-Shen Chiang ${ }^{3}$. Ching-Syang Jack Yue ${ }^{4,5} \cdot$ Hsiu-Te Sung $^{1} \cdot$ Chun-Hsin Chang ${ }^{6}$}

1 Department of Industrial Education, National Taiwan Normal University, 162, Sec. 1, Heping E. Rd., Taipei, Taiwan

2 College of Education and Human Ecology Department, The Ohio State University, 1945 North High Street, Columbus, OH, USA

3 Department of International and Comparative Education, National Chi-Nan University, 1, University Rd., Puli, Taiwan

4 Department of Statistics, National Chengchi University, 64, Sec. 2, ZhiNan Rd., Taipei, Taiwan

5 Research Center for Nonlinear Analysis and Optimization, Kaohsiung Medical University, Kaohsiung, Taiwan

6 Undergraduate Program of Vehicle and Energy Engineering, National Taiwan Normal University, 162, Sec. 1, Heping E. Rd., Taipei, Taiwan 